\title{
Amisulpride withdrawal dyskinesia: a case report
}

Yu-Chi Lo ${ }^{1 *}$ and Ying-Chieh Peng ${ }^{2}$

\begin{abstract}
Background: The effects of antipsychotic drug withdrawal have been inadequately studied. Case reports have described dyskinesia occurring in patients with several antipsychotics withdrawn, but studies on amisulpride withdrawal dyskinesia are lacking.

Case presentation: A 63-year-old man, who was diagnosed with schizophrenia at age 49, received amisulpride treatment since age 62. The dosage of amisulpride was reduced from 200 to $50 \mathrm{mg} /$ day because of occurrence of akathisia during one admission. Severe withdrawal dyskinesia, mixed with dystonia and akathisia, was noted immediately after the dosage reduction. The abnormal involuntary movement showed improvement 2 weeks later when the dosage was increased to $100 \mathrm{mg} /$ day.

Conclusions: Withdrawal dyskinesia and other abnormal involuntary movements could be noted in a patient with reduction of amisulpride dosage or sudden termination. Withdrawal dyskinesia may subsequently lead to persistent tardive dyskinesia. Therefore, withdrawal-emergent dyskinesia should be promptly identified, and appropriate medical interventions should be given early.
\end{abstract}

Keywords: Amisulpride, Antipsychotics, Withdrawal, Dyskinesia, Side effects, Schizophrenia, Case report, Abnormal involuntary movement

\section{Background}

Several chronic schizophrenic patients require antipsychotic maintenance treatment. Discontinuation of antipsychotics in patients with schizophrenia often leads to increased risk of psychotic relapse. However, the effects of antipsychotic drug withdrawal have not been adequately studied. A recent investigation indicated that patients experienced a range of discontinuation symptoms, including physical, cognitive, emotional, psychotic or sleep-related disturbances [1]. Therefore, more attention should be paid to discontinuation symptoms to identify the discomfort suffered by patients withdrawn from antipsychotics. Case reports have described dyskinesia occurring in patients with several antipsychotics withdrawn, but studies on amisulpride withdrawal dyskinesia are lacking.

\footnotetext{
*Correspondence: ray7040@hotmail.com

${ }^{1}$ Ministry of Health and Welfare Kinmen Hospital, No. 2, Fuxing Rd., Jinhu

Township, Kinmen County 89142, Taiwan

Full list of author information is available at the end of the article
}

\section{Case presentation}

A 63-year-old man was diagnosed with schizophrenia at age 49 and had been treated at the outpatient department of Songde Branch of Taipei City Hospital since the diagnosis. His symptoms included delusional jealousy, persecutory delusion, irritability, self-destructive behaviour and self-talk. Sulpiride $600 \mathrm{mg} /$ day was prescribed but he quit the outpatient follow-up 2 months later. From age 50 , he had an average daily consumption of four standard drinks of alcohol. Drinking worsened his impulse control and caused him to get into conflicts with his neighbours. He had been admitted to the acute psychiatric ward of Songde Branch of Taipei City Hospital three times since age 55 . Brain computed tomography was performed that showed mild bilateral frontal lobe atrophy, but no other significant abnormal findings were identified. Benzodiazepine and thiamine were given whenever he was admitted for the prevention of Wernicke's encephalopathy and alcohol withdrawal symptoms. Neither acute confusion state nor obvious amnesia was noted during admission. 
Risperidone $4 \mathrm{mg} /$ day was used at first during admission for about 1 month with significant improvement in his psychotic symptoms. Unfortunately, the side effect dysphasia occurred and the patient developed aspiration pneumonia. Therefore, risperidone treatment was ceased and quetiapine was prescribed with gradual increase in dosage to about $550 \mathrm{mg} /$ day. However, the treatment efficacy was not satisfactory in this patient.

At age 62, amisulpride at a dosage of $400 \mathrm{mg} /$ day was prescribed instead in the outpatient department. After 6 months, obvious akathisia was noted, and he was transferred to Bali psychiatric centre for further treatment. The amisulpride dosage was tapered to $200 \mathrm{mg}$ /day. His psychotic symptoms remained stable, but the side effects persisted, and amisulpride was further reduced to $50 \mathrm{mg} /$ day gradually. His akathisia showed improvement, but he began to suffer from other forms of abnormal involuntary movements comprising dyskinesia mixed with dystonia and akathisia. The involuntary movements involved his trunk, head and neck, and four limbs. He kept twisting his body and head around or back and forth (Additional file 1: Video 1), which may be the dyskinesia symptoms mixed with the cervical dystonia. Further, the feeling of inner restlessness and a compelling need to be in constant motion meant that akathisia played a role in his abnormal involuntary movements. Meanwhile, the stepping movement could also be observed when he was made to sit (Additional file 1: Video 1). According to the patient and his family's report, the abnormal involuntary movements, which were subsequent to the dosage reduction of amisulpride, never occurred previously.

The symptoms persisted for 2 weeks until amisulpride was increased to $100 \mathrm{mg} /$ day. He still had slightly involuntary movement of his head and body but with much declined severity (Additional file 2: Video 2). Besides the adjustment of antipsychotic dosage, we used propranolol $10 \mathrm{mg}$ twice a day for treatment of his akathisia and biperiden $0.5 \mathrm{mg}$ twice a day for some dystonia-like symptoms. Further, lorazepam ( $0.5 \mathrm{mg}$ twice a day) was prescribed for supplementary treatment of akathisia and dyskinesia for about 2 weeks. After discharge, the patient got relapsed about 1 year later with poor treatment adherence. The abnormal involuntary movements were still noted, although very mild, even though he did not take any psychotropic medications for about 3 months.

\section{Discussion}

Withdrawal-emergent syndrome was first described in 1973 by Polizos et al. [2] as choreatic movements in children after abrupt discontinuation of an antipsychotic drug after long-term use. The symptoms usually manifest during the first few days or weeks after discontinuation of dopamine receptor-blocking agents. It is believed to be caused by a temporary hyper-dopaminergic state in the basal ganglia following the discontinuation of dopamine receptor-blocking drugs [3]. Further, the most prominent theories on tardive dyskinesia pathogenesis could account for the occurrence of withdrawal dyskinesia. The theories indicate that chronic exposure to neuroleptics results in D2 receptor upregulation with postsynaptic dopamine receptor supersensitivity. D2 receptors are inhibitory receptors expressed on medium-spiny neurons that project onto the indirect pathway; hence, their hypersensitivity can result in disinhibition of the globus pallidus internus and the subthalamic nucleus, producing a variety of hyperkinetic movement disorders [4].

Case reports have described dyskinesia occurring after withdrawal of different antipsychotics, including chlorpromazine and fluphenazine [5], mesoridazine [6], haloperidol [7, 8], risperidone [9-12], aripiprazole [12-14] and clozapine [15]. However, there is no literature on amisulpride withdrawal dyskinesia. The present case illustrated that dyskinesia does occur in patients withdrawn from amisulpride.

Gardos et al. [3] classified the dyskinetic movements seen during antipsychotic treatment into the following three distinct categories: tardive dyskinesia, withdrawal dyskinesia and covert dyskinesia. Withdrawal dyskinesia, in contrast to tardive dyskinesia, is self-limited, whereas covert dyskinesia refers to a dyskinesia that develops in response to dose reduction or drug discontinuation, does not disappear spontaneously and may become permanent. It has been suggested that if withdrawal dyskinesia does not subside within 12 weeks, it is likely to be a covert dyskinesia [3].

Some studies have indicated that withdrawal-emergent movements in subjects who are not yet diagnosed with tardive dyskinesia (TD) may represent an early phase of neurological dysfunction on a continuum ultimately leading to persistent TD [16-18]. Therefore, antipsychotic withdrawal-emergent dyskinesia should be promptly identified and appropriate medical interventions should be taken as early as possible. These interventions may include minimising the dosage of medication, switching from a conventional to an atypical antipsychotic and prescribing quetiapine or clozapine instead $[18,19]$, although clozapine-withdrawal dyskinesia has also been reported [15]. In addition, other less studied medications that may provide various degrees of symptomatic improvement in TD could be considered to alleviate withdrawal dyskinesia. These medications include amantadine that acts as a glutamate receptor-blocking agent [20] and gamma-aminobutyric acid (GABA) agonistic medications such as benzodiazepines [21], lithium [22], vitamin E [23], melatonin [24] and zolpidem [25]. Nevertheless, all these observations are from small open-label studies and case reports. 
As for the present case described here, he got relapsed and was admitted to our acute psychiatric ward 1 year after last discharge. He did not take any psychotropic medications for about 3 months; however, a mild form of truncal and neck dyskinesia could still be observed. This was probably consistent with the 'covert dyskinesia' mentioned by Gardos et al. [3].

There is a limitation of the case report. Neurodegenerative process at the age of 63 would represent a potential cause regarding the development of dyskinesia; however, we did not arrange dopamine imaging for him. The reason was that the neurological examinations at admission did not show focal neurological signs or obvious abnormal involuntary movements except akathisia. The abnormal involuntary movements were noted immediately after the dosage reduction, and it never occurred previously. Therefore, other neurodegenerative diseases were not favoured, and the dopamine imaging was not performed. Thus, neurodegenerative disease induced dyskinesia could not be ruled out completely.

\section{Conclusion}

Withdrawal dyskinesia could be noted in patients with reduction in amisulpride dosage or sudden termination. Previous case reports included withdrawal of both typical and atypical antipsychotics. Some studies indicated that antipsychotic withdrawal-emergent movements in patients may subsequently lead to persistent TD. Therefore, withdrawal-emergent dyskinesia should be promptly identified, and appropriate medical interventions should be given as early as possible.

\section{Additional files}

Additional file 1: Video 1. The abnormal involuntary movements after withdrawal of amisulpride.

Additional file 2: Video 2. The abnormal involuntary movements showed improvement when the dosage of amisulpride was increased.

\section{Abbreviation}

TD: tardive dyskinesia.

\section{Authors' contributions}

YCL and YCP both contributed to conception and design, drafting and revising the manuscript. Both authors read and approved the final manuscript.

\section{Author details \\ ${ }^{1}$ Ministry of Health and Welfare Kinmen Hospital, No. 2, Fuxing Rd., Jinhu Township, Kinmen County 89142, Taiwan. ${ }^{2}$ Bali Psychiatric Center, No. 33 Huafushan, Bali Dist., New Taipei City 24936, Taiwan.}

\section{Acknowledgements}

We thank the clinicians and the ward staff that were involved in the treatment of the patient at the Bali Psychiatric Center of Taiwan.

\section{Competing interests}

The authors declare that they have no competing interests.

\section{Availability of data and materials}

This is a single-patient case report. Data sharing is not applicable to this article as no datasets besides those reported in the article were generated or analysed in the current study.

\section{Consent for publication}

Written informed consent was obtained from the patient for the case report, including the videos.

\section{Publisher's Note}

Springer Nature remains neutral with regard to jurisdictional claims in published maps and institutional affiliations.

Received: 25 February 2017 Accepted: 8 June 2017

Published online: 14 June 2017

\section{References}

1. Salomon C, Hamilton B, Elsom S. Experiencing antipsychotic discontinuation: results from a survey of Australian consumers. J Psychiatr Ment Health Nurs. 2014;21:917-23.

2. Polizos P, Engelhardt DM, Hoffman SP, Waizer J. Neurological consequences of psychotropic drug withdrawal in schizophrenic children. J Autism Child Schizophr. 1973;3:247-53.

3. Gardos G, Cole JO, Tarsy D. Withdrawal syndromes associated with antipsychotic drugs. Am J Psychiatry. 1978;135:1321-4.

4. Teo JT, Edwards MJ, Bhatia K. Tardive dyskinesia is caused by maladaptive synaptic plasticity: a hypothesis. Mov Disord. 2012;27:1205-15.

5. Thornton WE, Thornton BP. Tardive dyskinesias from the major tranquilizers. J Fla Med Assoc. 1973:60:24-6.

6. Marcotte DB. Neuroleptics and neurological reactions. South Med J. 1973;66:321-4.

7. Crane GE. Rapid reversal of tardive dyskinesia. Am J Psychiatry. 1973;130:1159.

8. Jacobson G, Baldessarini RI, Manschrek T. Tardive and withdrawal dyskinesia associated with haloperidol. Am J Psychiatry. 1974;131:910-3.

9. Alblowi MA, Alosaimi FD. Tardive dyskinesia occurring in a young woman after withdrawal of an atypical antipsychotic drug. Neurosciences. 2015;20:376-9.

10. Komatsu S, Kirino E, Inoue Y, Arai H. Risperidone withdrawal-related respiratory dyskinesia: a case diagnosed by spirography and fibroscopy. Clin Neuropharmacol. 2005;28:90-3.

11. Anand VS, Dewan MJ. Withdrawal-emergent dyskinesia in a patient on risperidone undergoing dosage reduction. Ann Clin Psychiatry. 1996;8:179-82.

12. Urbano M, Spiegel D, Rai A. Atypical antipsychotic withdrawal dyskinesia in 4 patients with mood disorders. J Clin Psychopharmacol. 2007;27:705-7.

13. Philip NS. An aripiprazole discontinuation syndrome. R I Med J. 2013;96:13-4.

14. Moseley CN, Simpson-Khanna HA, Catalano G, Catalano MC. Covert dyskinesia associated with aripiprazole: a case report and review of the literature. Clin Neuropharmacol. 2013;36:128-30.

15. Ahmed S, Chengappa KN, Naidu VR, Baker RW, Parepally H, Schooler NR. Clozapine withdrawal-emergent dystonias and dyskinesias: a case series. J Clin Psychiatry. 1998;59:472-7.

16. Perényi A, Frecska E, Bagdy G, Révai K. Changes in mental condition, hyperkinesias and biochemical parameters after withdrawal of chronicneuroleptic treatment. Acta Psychiatr Scand. 1985;72:430-5.

17. Kane JM, Woerner M, Lieberman J. Tardive dyskinesia: prevalence, incidence, and risk factors. J Clin Psychopharmacol. 1988;8:52S-6S.

18. Schultz SK, Miller DD, Arndt S, Ziebell S, Gupta S, Andreasen NC. Withdrawal-emergent dyskinesia in patients with schizophrenia during antipsychotic discontinuation. Biol Psychiatry. 1995;38:713-9.

19. Emsley R, Turner HJ, Schronen J, Botha K, Smit R, Oosthuizen PP. A singleblind, randomized trial comparing quetiapine and haloperidol in the treatment of tardive dyskinesia. J Clin Psychiatry. 2004;65:696-701. 
20. Angus S, Sugars J, Boltezar R, Koskewich S, Schneider NM. A controlled trial of amantadine hydrochloride and neuroleptics in the treatment of tardive dyskinesia. J Clin Psychopharmacol. 1997;17:88-91.

21. Thaker GK, Nguyen JA, Strauss ME, Jacobson R, Kaup BA, Tamminga CA. Clonazepam treatment of tardive dyskinesia: a practical GABAmimetic strategy. Am J Psychiatr. 1990;147:445-51.

22. Van Harten PN, Hoek HW, Matroos GE, van Os J. Evidence that lithium protects against tardive dyskinesia: the Curaçao Extrapyramidal syndromes study VI. Eur Neuropsychopharmacol. 2008;18:152-5.
23. McGrath J, Soares-Weiser K. Vitamin E for neuroleptic-induced tardive dyskinesia. Cochrane Database Syst Rev. 2011;16:000209.

24. Shamir E, Barak Y, Shalman I, Laudon M, Zisapel N, Tarrasch R, Elizur A, Weizman R. Melatonin treatment for tardive dyskinesia: a doubleblind, placebo-controlled, crossover study. Arch GenPsychiatry. 2001;58:1049-52.

25. Waln O, Jankovic J. Zolpidem improves tardive dyskinesia and akathisia. Mov Disord. 2013;28:1748-9.

\section{Submit your next manuscript to BioMed Central and we will help you at every step:}

- We accept pre-submission inquiries

- Our selector tool helps you to find the most relevant journal

- We provide round the clock customer support

- Convenient online submission

- Thorough peer review

- Inclusion in PubMed and all major indexing services

- Maximum visibility for your research

Submit your manuscript at

www.biomedcentral.com/submit 